\title{
Household energy use: a study investigating viewpoints towards energy efficiency technologies and behaviour
}

\author{
Marcos Pelenur (iD
}

Received: 28 October 2016 / Accepted: 22 January 2018 / Published online: 13 February 2018

(C) The Author(s) 2018. This article is an open access publication

\begin{abstract}
Improving the energy efficiency of our homes presents an excellent opportunity to reduce greenhouse gas emissions and increase thermal comfort. However, a shortfall exists between the full potential and realised adoption of energy efficiency measures, a phenomenon termed the 'Energy Efficiency Gap'. To better understand the energy efficiency gap, this research identified household viewpoints towards energy and stated preferences towards energy efficiency technologies and behaviour. The research was carried out through interviews and a Q study in the cities of Manchester and Cardiff, alongside a questionnaire. The results revealed a range of nuanced viewpoints, which mapped onto three principal household themes: energy use in terms of the environment, energy in relation to money and apathy towards energy. A key finding was the small number strong correlations between distinct energy viewpoints and specific energy efficiency technologies or behaviours. This result implies that being environmentally aware and actively concerned about energy efficiency does not in itself lead to a stated desire, or even, intention to install energy-efficient technologies. The wider implication is that households that hold proactive energy efficiency viewpoints based on environmental concern may still require specifically targeted incentives to encourage
\end{abstract}

M. Pelenur $(\bowtie)$

Department of Engineering, Centre for Sustainable Development, University of Cambridge, Cambridge, UK

e-mail: mpelenur@cantab.net the uptake of energy efficiency measures, i.e. their proactive and environmental beliefs are not alone enough to motivate them to improve the energy efficiency of their home.

Keywords Subjectivity Q methodology · Energy efficiency gap $\cdot$ Retrofit $\cdot$ Behaviour change

\section{Introduction}

The existing building stock in European countries accounts for over $40 \%$ of final energy consumption, of which residential use represents $63 \%$ of total energy consumption in the buildings sector (Balarasa et al. 2007). In the UK, the built environment accounts for about $45 \%$ of its anthropogenic $\mathrm{CO}_{2}$ emissions (Kelly M. J. 2009; Lior 2010) and 50\% of the total UK energy demand (Lior 2010). For homes, space and water heating account for the bulk of energy use, at approximately 72\%. (Department of Environment, Food and Rural Affairs 2007; Department of Energy and Climate Change 2012; Kelly M. J. 2009). As such, installing energy efficiency measures in residential dwellings presents an excellent opportunity to cut $\mathrm{CO}_{2}$ emissions, reduce national energy demand and improve building performance (Kelly M. J. 2009; Stafford, Gorse and Shao 2012).

Yet, despite these benefits, there exists a shortfall between the potential and realised adoption of energy efficiency measures, a phenomenon termed the 'Energy Efficiency Gap' (Jaffe and Stavins 1994; Pelenur M. 
2013). In OECD countries, the energy savings loss due to the energy efficiency gap is estimated at $30 \%$ of the total potential energy savings of the measures (Weber, 1997). While a number of technical or economic factors may help explain this gap, difficult to quantify factors, such as social motivations, barriers and viewpoints towards energy are also significant and often underemphasised in public policy (Pelenur M. 2013).

A number of studies investigated viewpoints towards residential energy use, but they often focused on individual issues such as wind or solar power (Eltham et al., 2008; Jones and Eiser 2009; Krohn and Damborg 1999). Alternatively, other research used environmental viewpoints as a proxy towards energy use (Zhang et al., 2012; Mansouri et al., 1996), while engineering-based research often tried to capture behaviour as a variable within a model (Druckman and Jackson 2008; Swan and Ugursal, 2009). The result is that researchers may have overlooked other important factors that relate to energy use. Therefore, to address this gap, this study investigated broad household viewpoints towards energy use and linked them to technical retrofit preferences and energy efficiency behaviours in a UK context. The research was carried out through the use of interviews, a Q study and a questionnaire. Q methodology was developed in 1952 by William Stephenson (psychologist and physicist) as a research method used to study the 'subjectivity' or viewpoints of specific topics. Since then, it has been adopted by a range of disciplines.

The intended outcome of this research is to better understand how we may overcome the energy efficiency gap and help increase the adoption of residential retrofit programmes to improve the energy performance of the built environment. This research is relevant to policy makers, professionals and academics working to promote energy efficiency in the built environment.

The remainder of the paper is split into five sections: first, a background describing the relevant scholarship; second, an outline of the adopted research method; third, a presentation of the results; fourth, a discussion of the research with implications for policy and fifth, a conclusion.

\section{Background}

Retrofitting the UK residential built environment to improve its energy performance is a complex challenge, exasperated by many factors including the diversity of the UK building stock and range of occupant behaviour (Stafford, Gorse and Shao 2012). With respect to homes, the UK has some of the oldest and most energyinefficient stock in Europe (Meijer et al., 2009). Adding to the complexity is the estimate that between 70 and $80 \%$ of the existing poorly performing buildings will still be in use in 2050 (Kelly 2009, 2010; Institution of Mechanical Engineers 2009; Stafford et al. 2012; Dixon and Eames 2013). In response to this challenge, the UK government introduced a range of programmes over time, such as the following: the Carbon Emissions Reduction Target (CERT); Community Energy Saving Programme (CESP); Decent Homes; Warm Front and the Green Deal. However, many of these programmes focus only on financial incentives and do not address other factors that may be barriers or motivations to the uptake of energy efficiency measures, such as social norms or viewpoints towards energy (Pelenur and Cruickshank 2012; Pelenur and Cruickshank 2014). In order to better understand energy consumption in the home across a broad range of factors, Lutzenhiser (1992) introduced an energy culture framework that took into account social norms and culture alongside the more traditional econometrics. The energy culture framework was extended by Stephenson et al. (2010) to apply to consumer energy behaviour, by specifically examining the interactions between cognitive norms (e.g. beliefs, understandings), material culture (e.g. technologies, building form) and energy practices (e.g. activities, processes). This framework can be applied to individuals and households, as well as neighbourhoods and communities.

This research was guided by the energy culture framework to better understand the relationship between residential occupant viewpoints and energy efficiency retrofits. An aspect of household cognitive norms was explored through the use of a Q study that identified subjective viewpoints, while the household material culture and energy practices were captured through interviews and a questionnaire. For this research, the definition of 'viewpoint' was taken from Q methodology, which defines it as simply the sum of behavioural activity that constitutes a person's point of view (Watts and Stenner, 2012). This definition is related to, but different, to other existing definitions for 'attitudes' or 'perspectives'. To avoid confusion, this article only refers to viewpoints as defined by Q methodology.

To support the Q study, a questionnaire was administered to measure household demographics, 
as well as the stated desire and intention to install various energy efficiency technologies. The design of the questionnaire was influenced by the theory of reasoned action (TRA) and theory of planned behaviour (TPB) that both suggest that the level of 'intentions' shown by an individual is the best predictor of their behaviour (Jackson 2004Kaiser et al., 1999; Kalafatis et al., 1999). Both theories have been used to model behaviour over a wide range of topics, particularly pro-environmental behaviour (Jackson 2004). However, there is also often a sizeable discrepancy between peoples' selfreported knowledge, values and intentions and their described behaviour; well-known examples include the 'knowledge-action gap' and 'value-action gap' (Frederiks et al., 2015).

As such, this study did not infer that the stated answers on the questionnaire necessarily led to behaviour change. Instead, the purpose of the questionnaire was to reveal potentially interesting relationships between the Q study factors (viewpoints) and various energy efficiency technologies/behaviours. Such relationships help with the possible interpretation of the Q factors.

After the oil shock of the 1970s, there was a marked increase of research towards environmental beliefs and viewpoints towards energy use. For example, research in the USA found that over three quarters of individuals felt personally responsible for solving the energy crisis and held strong environmental beliefs (Olsen 1981). The results from another study, which investigated the impact that fear had on attitudes towards energy use, found that increasing the perceived likelihood of an energy shortage did not affect attitude, but that increasing the perceived noxiousness or severity of an energy crisis strengthened intentions to reduce energy consumption (Hass et al., 1975). In terms of technological attitudes, another American study found no link between general viewpoints towards technology and conservation behaviour (Anderson and Lipsey 1978). The 1970s oil crisis showcased how large global events can influence viewpoints towards energy use, with the Fukushima Daiichi nuclear disaster as a more recent example that resulted in stronger anti-nuclear sentiments (Visschers and Siegrist, 2013. This highlights how research investigating subjectivity is a product of its time and may need to be revisited in light of substantial external stimuli.

Alongside environmental stimuli, local context is also an important factor to consider alongside viewpoints towards energy (Lutzenhiser 1992; Owens and Driffill 2008; Shove et al., 1998). For example, a Canadian study examined the relationship between residential winter energy use and viewpoints and found that thermal comfort was the most important determinant of household energy use (Becker et al., 1981). Alternatively, other studies found a wide range of sociodemographic variables more significant in determining household energy use (Abrahamse and Steg 2009; Guefin et al., 2000; Ritche et al., 1981). Although it is interesting to note that thermal comfort was also strongly associated with viewpoints towards energy use in a Texas study (Samuelson and Biek 1991). Even though the Canadian and Texas study conclusions were broadly similar, the interpretation of the results were quite different given that thermal comfort in Canada is largely defined by heating, whereas air conditioning determines thermal comfort in Texas. Such detailed differences highlight the need to understand and present local context before attempting to interpret social research.

In the UK, the Department of Food and Rural Affairs (Defra) conducted a range of research to better understand pro-environmental behaviour and attitudes and investigate how those attitudes can be used to encourage sustainable energy consumption at home (Department of Environment, Food and Rural Affairs 2007; Department of Environment, Food and Rural Affairs 2008). Their results segmented the population into seven major groups according to their environmental values, namely: greens; consumers with a conscience; wastage focused; currently constrained; basic contributors; long-term restricted; and disinterested (Department of Environment, Food and Rural Affairs 2007). The studies were detailed; however, they focused mostly on environmental viewpoints and may have missed other relevant factors that impact household energy use (Pelenur, 2013). Very few studies have sought to specifically identify broad viewpoints towards residential energy use and investigate how those viewpoints may be associated with different retrofit technologies. To address this research gap, this study identified broad household viewpoints towards energy use and linked them to technical retrofit preferences and energy efficiency behaviours in a UK context. The purpose of this research was to better understand how we may overcome the energy efficiency gap and help improve the adoption of residential retrofits. 


\section{Research method}

This section first outlines the rationale for selecting Manchester and Cardiff as case studies and then describes how the Q study, questionnaire and interviews were designed and administered in each city.

This research was part of the research project 'ReEngineering the City 2020-2050 Urban Foresight and Transition Management (RETROFIT 2050)' and adopted a case study approach to better understand the complex challenge associated with retrofitting the residential built environment (Pelenur, 2013). A case study designs allows researchers to investigate a contemporary phenomenon within its real-life context, especially when the boundaries between phenomenon and context are not clearly evident and in which multiple sources of evidence are used (Yin, 2009).

The cities of Cardiff and Manchester were selected as case studies because both have long strong roots with the industrial revolution, yet both have suffered a decline in recent decades and are now seeking to regenerate themselves into thriving cities (RETROFIT 2050 2012). Manchester and Cardiff also present large and substantial opportunities to improve the UK's residential energy performance. Specifically, within Greater Manchester, $25 \%$ of the housing stock is of solid wall construction and there are still 500 thousand untreated lofts and cavity walls (Low Carbon Housing Retrofit 2012). In Wales, only approximately $18 \%$ of homes have cavity wall and loft insulation fitted (National Refurbishment Centre 2012). Both cities are also similar in size, with approximately 145 thousand dwellings in the unitary authority of Cardiff and 200 thousand dwellings in the metropolitan district of Manchester (Office for National Statistics 2013).

\section{Q study design}

The viewpoints towards energy use in the home were collected through a Q study with 91 participants and the stated intent and desire to install various energy efficiency technologies/behaviours were measured through an accompanying questionnaire. Q methodology (Q) was selected because of its parsimonious strength to explore subjective topics and identify complex viewpoints, while a questionnaire was used to simplify the measurement of technology/behaviour preference. The questionnaire also included questions about important physical household characteristics and demographics. Q methodology approaches the study of subjectivity by examining it through the analysis of individual choices and actions, as opposed to interviews which often take stated responses at face value. For example, with a relatively small Q-set of only 33 statements, the cognitive ranking task still presents participants with roughly 11,000 times as many [sorting] options as there are people in the world (Watts and Stenner, 2012).

To evaluate the results of $Q$, the methodology uses a by-person factor analysis to identify groups of participants who rank and make sense of statements in a comparable way (Watts and Stenner 2012). This is different to other quantitative methods, such as regression analysis, which identifies and combines sets of dependant variables to statistically correlate relationships between similar things. Participant interviews supplement the factor analysis and enable the results to be interpreted through a qualitative lens, thereby establishing patterns within and across individuals rather than patterns across individual traits, such as gender, age or class (Barry and Proops 1999). As an exploratory methodology, Q cannot prove hypotheses; however, it can help bring a sense of coherence to complex research questions with socially contested answers (Smith et al., 1995).

Q methodology has been applied to a range of topics with inherit subjectivity, such as investigating viewpoints towards nuclear energy and teen pregnancy.

\section{Sample selection}

The participants (P-set) for this study were drawn from four areas in Cardiff and four areas in Manchester. The areas were selected to closely match each cities' average demographic and census profile, through a statistical standardisation method. As such, these areas represented 'typical' neighbourhoods in Manchester and Cardiff, insofar as being associated with census averages, such as the following: home type, tenure, number of bedrooms and population. This was deliberate sampling in order to investigate viewpoints from 'typical' neighbourhoods in each city. This 'typical' setting was selected as the context for this study so that the results may be more representative of an average UK city and therefore applied to other areas. However, it may be interesting for future research to investigate and contrast viewpoints from fringe communities.

In total, there were 10,908 households in the 4 areas of Cardiff and 12,667 households in Manchester. 
Although this total number of households was not important to the research design; rather, it was a consequence of the size of the statistical output areas used to identify the typical neighbourhoods. Leaflets offering a chance to win $£ 250$ in grocery vouchers for participating in the study were delivered to all the homes, followed by 2 days of door canvassing. The goal was to recruit about ten participants from each of the areas. Nearly all of the participants were recruited through door knocking, with a total of 46 participants in Manchester and 45 in Cardiff. This type of non-probabilistic sampling is the norm in Q (Brown 1980; Wilson and Dowlatabadi, 2007), where participants are usually chosen based on an a priori theoretical design, rather than representativeness or quantity (Eden et al., 2005). Participants for this study were chosen by first identifying 'typical' neighbourhoods and then recruited. However, it is possible to for future studies to use other selection criteria that may relate to a household's cognitive norms or demographics.

The final sample between Manchester and Cardiff were broadly similar, with some expected deviations between the cities. The sample demographics are discussed in more detail in the results section.

\section{Administering the Q study}

Each of the 91 participants took part in the Q study. Prior to administering the Q study in Manchester and Cardiff, two Q study pilots were conducted with 14 participants in Cambridge and London. The participants were a mix of individuals with no Q methodology knowledge and experienced Q practitioners. The aim of the pilots was to test the research instruments, specifically the comprehensiveness of the Q-set and validity of the questionnaire. The pilot was a full simulation of the Q study conducted in Manchester and Cardiff, and as a result, changes were made to the wording in Q-set and questionnaire to improve readability and clarity.

As presented by (Barry and Proops 1999), the general steps to a Q Study are shown below. These steps are kept intentionally simple for brevity and should not be used as a guideline in isolation (instead, see Brown (1980) and Watts and Stenner, 2012for a more detailed overview of Q).

The first step is to identify the area of subjective 'discourse' to explore, for this study, the discourse was household viewpoints relating to energy use in Cardiff and Manchester. The next step is to widely research existing ideas on the discourse through the use of interviews, focus groups or discussions with the relevant population. The main objective of this step is to create a comprehensive and representative list of opinions on the topic.

The discourse for this Q study was derived from the transcripts of general public semi-structured interviews conducted in Manchester and Cardiff, as well as from the transcript of a multi-day workshop with energy retrofit professionals. These interviews were conducted prior to the Q study. In total, 198 public interviews were collected across multiple areas of the cities. The interview questions were worded to encourage the respondent to adopt a 'household' viewpoint so that the results not only included individual behaviours, but also insights into how relationships between family members or multi-tenanted homes affect energy demand. The interviews were piloted first to ensure the wording of the questions could easily be understood by participant, yet open enough to allow for varied responses (Pelenur and Cruickshank 2011).

The Manchester and Cardiff interviews were then transcribed and analysed to generate single-idea Q statements (Q-set) used to represent the discourse. In total, approximately 200 suitable statements were identified after removing obvious duplications. This list of 'raw' statements were grouped into themes according to an inductive and structured Q-set approach as described by McKeown and Thomas (1988). In order to select only the most salient statements from each theme and ensure an approximately equal distribution, the complete list of Q statements (grouped by theme) was shown to nonacademic volunteers unfamiliar with Q methodology. The statements that the volunteers felt were the easiest to understand and relevant to the topic (energy consumption in the home) were selected. The final Q-set consisted of 65 statements is shown in Table 7 (see Appendix).

With the full Q-set of statements, and after the pilot, each of the 91 participants in Manchester and Cardiff performed an individual Q-sort, where they received an instruction and ranked the statements onto a quasinormal forced distribution using a scale from -6 (most disagree) through 0 to +6 (most agree) (Watts and Stenner 2012). The specific condition of instruction for this Q study was 'use the statements in the Q-Sort to indicate your personal views about energy use in your home. Sort the items according to those which you most 
agree (+6) to those with which you most disagree (-6). The term 'energy' is meant to represent primary and secondary energy sources (natural gas, coal, electricity, etc).'. Figure 1 is an illustrative example of a participant performing a Q-sort.

After performing the Q-sorts, a semi-structured interview was also conducted with each participant before administering the questionnaire. The aim of the interview was to understand why participants sorted the statements the way they did and to ensure that their viewpoint was adequately represented in the Q-sort. Specifically, the qualitative interview data provided context for the interpretation of the quantitative Q study results.

The total set of Q-sorts (91) were then statistically analysed through a by-person factor analysis to identify significant factors and then quantitatively and qualitatively interpreted into viewpoints and compared for similarities/differences. The quantitative data was used to statistically measure the relationship between individual Q-sorts and factors, while the interview transcripts were used to provide the context as to why participants chose their final sorts. Because Q methodology uses a by-person factor analysis, it offers the advantage of needing only a small sample to explore subjective topics and identify complex viewpoints.

\section{Administering the questionnaire}

The accompanying questionnaire was completed after each Q-sort and measured the desire to install or adopt a range of energy efficiency technologies and/or behaviours as well as the participant's stated intent to do so. The questionnaire also captured personal and household demographics. The distinction between 'desire' and 'intent' was intentional, in order to capture situations when a participant wanted to install/adopt a certain technology/behaviour ('desire'), but could not do so ('intent'). For example, some participants stated their desire to install solar photovoltaic systems to generate electricity, but could not do so because of the cost or due to being a tenant (low 'intent'). The questionnaire also provided an open text box to note differences between intent and desire, and any motivations or barriers to adopting the technology/behaviour. If there were any technologies or behaviours unfamiliar to the participant, they were asked to skip the question. After the questionnaire was administered, each response was reviewed together by the researcher and the participant to ensure that they understood the difference between 'intent' and 'desire' for installing/adopting energy-efficient technologies/behaviours.

In total, the questionnaire included 18 energy technologies, from the UK's Standard Assessment Procedure (SAP), and 7 energy efficiency behaviours, shown in Table 8(see Appendix). The technologies were taken from SAP since that is the main model used by the government for policy intervention, while the behaviours were inductively identified from the 198 general population interviews conducted previously in Manchester and Cardiff (Pelenur and Cruickshank 2011).

Linking the questionnaire with the Q study

To investigate the relationship between the results of the questionnaire with each Q-sort, tests of associations were carried out between the numerical Q factor loadings and the questionnaire responses. For this purpose, other studies have used ANOVA, MANOVA, Pearson's correlation and path analysis (Thomas and Baas, 1996; Kubier 2010; Thomas et al., 1993; Thomas et al., 1982). However,
Fig. 1 Example of a participant performing a Q-sort with cards. Source: http://www. betterevaluation. org/en/evaluationoptions/qmethodology

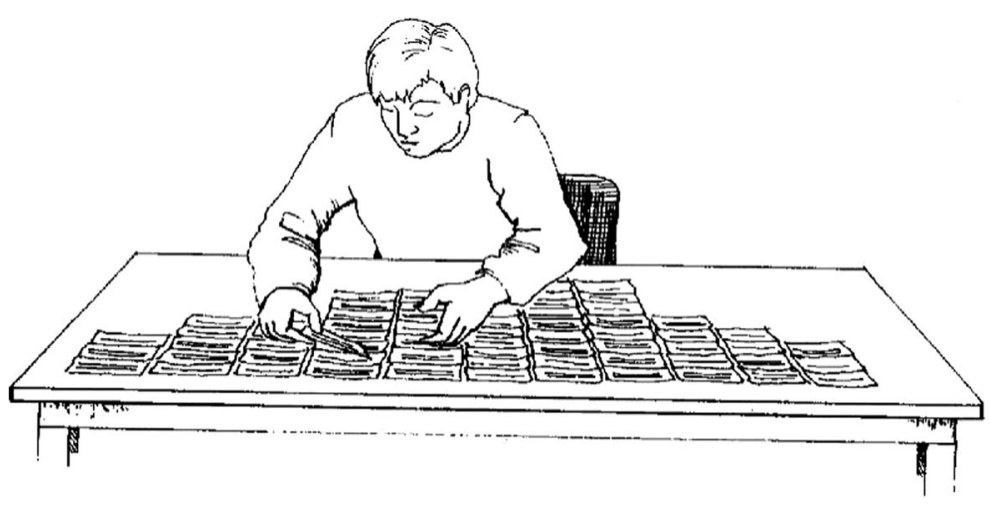


since the questionnaire variables in this study consisted of multiple data types, a range of correlation measures and test statistics were used to investigate the relationship between the numerical $\mathrm{Q}$ factor loadings and the questionnaire responses (Pelenur, 2013). Table 1 summarises the data types associated with each of the questionnaire variables and the test of association or test statistic used to correlate each variable with the numerical (interval/scale continuous) factor loadings from the Q study.

For all the listed tests of association, the null hypotheses $\left(H_{\mathrm{O}}\right)$ was no significant correlation between any of the questionnaire variables and the factor loadings, while the alternative hypothesis $\left(H_{\mathrm{A}}\right)$ was the existence of any correlation between the variables. Because there were multiple hypotheses testing between variables, the resulting $p$ value from each test was adjusted to correct for multiple comparisons. For this study, the BenjaminiHochberg procedure was used to adjust the final $p$ values and control the false discovery rate.

\section{Results}

Factor analysis

A total of 45 Q-sorts were completed in Cardiff and 46 in Manchester. Table 2 is the summary demographics for the participants in each city, as well as the percentages and averages for each city where available (percentages do not always sum to 100 due to rounding).
The sample demographics between Manchester and Cardiff were broadly similar, but there were some expected deviations between the sample and city averages. Most notably, there were many more married/common law Q-sort participants than the city averages. This was expected given that partners were often recruited for the Q study in tandem, in line with the goal of investigating how inter-household dynamics affected viewpoints towards energy use. The other notable difference was that not many participants under 30 were recruited, and due to the difficulty of recruiting in purpose built flats, there were more owner occupied non-flat residents than the average. However, the Q study sample still captured households from all the key demographics and was representative of the areas selected.

For Cardiff, the by-person factor extraction was done using centroid factor analysis (CFA) and judgement rotation, which is a common approach in $\mathrm{Q}$ methodology due to the flexibility it allows in relation to data exploration (Watts and Stenner, 2012). Four factors were identified in Cardiff: a dominant factor, a positive specificity, a negative specificity and a secondary factor. A specificity is defined as a factor where respondents that load significantly on it also agree with the main dominant factor (Brown 1980). In this way, specificities allow the researcher to examine a dominant theme from multiple sub-viewpoints. The Cardiff specificity was also bipolar, which means that it was defined by both positively and negatively loading Q-sorts (Watts and Stenner, 2012). Therefore, for analysis, the single bipolar

Table 1 Tests of associations used in study

\begin{tabular}{lll}
\hline Questionnaire variables & Data type & Test of association \\
\hline Technology/behaviour desire & Ordinal Likert item & Spearman's rho \\
Technology/behaviour intent & Ordinal Likert item & Spearman's rho \\
Installed/adopted (yes/no) & Dichotomous nominal & Point biserial \\
Sex & Dichotomous nominal & Point biserial \\
Age & Ordinal & Spearman's rho \\
Education level & Nominal & ANOVA $(F$ test $)$ \\
Marital status & Nominal & ANOVA $(F$ test $)$ \\
Household income & Ordinal & Spearman's rho \\
Tenure & Nominal & ANOVA $(F$ test $)$ \\
Type of home & Nominal & ANOVA $(F$ test $)$ \\
House age & Ordinal & Spearman's rho \\
Number of bedrooms & Interval & Pearson product-moment correlation \\
\hline
\end{tabular}


Table 2 Q study demographics

\begin{tabular}{|c|c|c|c|c|}
\hline Demographic variables & $\begin{array}{l}\text { Cardiff } \\
\text { sample (\%) }\end{array}$ & $\begin{array}{l}\text { Manchester } \\
\text { sample }(\%)\end{array}$ & Cardiff city & Manchester city \\
\hline \multicolumn{5}{|l|}{ Sex } \\
\hline Female & 60 & 52 & $51 \%$ & $50 \%$ \\
\hline Male & 40 & 48 & $49 \%$ & $50 \%$ \\
\hline \multicolumn{5}{|l|}{ Age } \\
\hline Under 30 & 7 & 7 & $45 \%$ & $50 \%$ \\
\hline $30-45$ & 33 & 39 & $20 \%$ & $22 \%$ \\
\hline $45-60$ & 36 & 39 & $17 \%$ & $14 \%$ \\
\hline Greater than 60 & 24 & 15 & $18 \%$ & $13 \%$ \\
\hline \multicolumn{5}{|l|}{ Marital status } \\
\hline Single/widowed & 33 & 35 & $61 \%$ & $70 \%$ \\
\hline Common law & 67 & 65 & $39 \%$ & $30 \%$ \\
\hline \multicolumn{5}{|l|}{ Type of dwelling } \\
\hline Flat/apartment & 11 & 11 & $27 \%$ & $35 \%$ \\
\hline Terrace (end or mid) & 36 & 48 & $30 \%$ & $30 \%$ \\
\hline Semi/detached house & 53 & 41 & $42 \%$ & $35 \%$ \\
\hline \multicolumn{5}{|l|}{ Tenure } \\
\hline Own & 76 & 65 & $59 \%$ & $38 \%$ \\
\hline Rent/live with family/friends & 24 & 35 & $41 \%$ & $62 \%$ \\
\hline \multicolumn{5}{|l|}{ Number of bedrooms } \\
\hline $1-2$ & 13 & 28 & (average) & (average) \\
\hline $3-4$ & 82 & 67 & 2.8 & 2.5 \\
\hline Greater than 4 & 4 & 4 & & \\
\hline \multicolumn{5}{|l|}{ Number of occupants } \\
\hline $1-2$ & 58 & 46 & (average) & (average) \\
\hline $3-4$ & 33 & 50 & 2.3 & 2.3 \\
\hline Greater than 4 & 9 & 4 & & \\
\hline \multicolumn{5}{|l|}{ Education level } \\
\hline Degree or more & 67 & 67 & & \\
\hline High school/trade & 33 & 33 & & \\
\hline \multicolumn{5}{|l|}{ Income } \\
\hline$£ 20 \mathrm{k}$ or less & 29 & 24 & & \\
\hline$£ 20 \mathrm{k}$ to $£ 40 \mathrm{k}$ & 20 & 26 & & \\
\hline$£ 40 \mathrm{k}$ to $£ 60 \mathrm{k}$ & 13 & 17 & & \\
\hline Greater than $£ 60 \mathrm{k}$ & 22 & 26 & & \\
\hline Refused & 16 & 7 & & \\
\hline
\end{tabular}

ter city averages: Office for

?National Statistics 2013 factor was separated into two unique factors to represent each of the poles. In order to identify statistically significant Q-sorts for each factor at $p<0.05$, the Q-sort loading value had to be greater than $|0.243|$ (Brown 1980). A higher significance level of 0.4 was used for the secondary factor in order to avoid conflating Q-sorts, i.e. Q-sorts that load onto more than one factor, while a significance level of 0.25 was used for the bipolar specificity.
As well as the four common Cardiff factors identified through CFA, a single participant (C13) was also visually identified during the judgement rotations as being of interest because their Q-sort was diametrically different from the others in the sample. Q methodology is well placed to the analysis of interesting single cases (Brown 1980), which are generally viewed as advancing knowledge about the process by which wider subjective worlds are constructed and experienced (McKeown 
and Thomas 1988). As such, the single Q-sort from participant $\mathrm{C} 13$ was analysed qualitatively and used to inform the discussion of the Cardiff results.

For Manchester, the data was less homogeneous and therefore easier to isolate separate factors. The Manchester factor analysis was initially done using CFA/ judgement rotation as well as a principal component analysis (PCA)/varimax rotation, which is a more mathematically precise solution but offers less flexibility with data exploration (Watts and Stenner, 2012). Both approaches yielded two clear factors, but the PCA solution with varimax rotation was selected because the factors were easier to isolate. In total, two factors were identified with a raised Q-sort significance level of 0.37 to reduce the instances of conflating sorts. The rotated factor loadings for each factor with flagged Q-sorts are shown in Table 9 (see Appendix).

The following narratives describe each of the factors for Cardiff and Manchester and were constructed through the interpretation of the factor arrays and postsort interview comments. Q statements used in the narratives are followed by their number and factor score in parenthesis. For readability, the phrasing of some statements were switched from positive to negative or vice versa signified by square brackets in the statement. This type of narrative design is a recognised method to present the results from a Q study (Watts and Stenner, 2012).

Cardiff factor 1 (dominant factor): I think about being energy efficient for the environment and greater good

Twenty-six participants' Q-sorts exemplified this factor, making this the dominant factor in the Cardiff study that accounted for $40 \%$ of the variance.

This factor exemplifies the household viewpoint that energy conservation can be driven by environmental issues, including climate change. The viewpoint also includes the idea of inter-generational responsibility and that energy efficiency should not be viewed as an inconvenience, rather as a standard expectation. As such, this factor includes many statements from the 'Environment and the future' theme. Mostly missing from the extreme ends of the factor array are statements regarding economics, finance and inefficient behaviours.

'I'm concerned about the effect of energy use on the atmosphere' $(21:+6)$ and can't understand how some people 'don't believe in climate change' (42: -6). Therefore because 'protecting the environment is important to me' $(27:+6)$, I strongly believe 'it's our responsibility to look after the next generation's future' $(49:+5)$, which is why 'parents should ensure that their kids are taught how to be energy efficient at home' $(9:+3)$. From a wider perspective, 'I'd like there to be more environmentally friendly sources of energy' $(13:+5)$ since 'we are too dependent on fossil fuels' $(16:+4)$, but 'the government is not doing enough about improving energy use' $(24:+5)$.

To do my bit at home, 'I rather use multiple blankets or put on more layers than turn up the heating' $(6:+1)$ but 'I believe the ever increasing number of gadgets is a problem for energy efficiency' $(54:+3)$. However, even though gadgets in the home are a problem for people in general, 'modern technology, such as plasma screens, are [not] more important to me than being energy efficient' (59: -5). Definitely 'the appearance of my home is [not] more important than being energy efficient' (17: -5) nor is 'trying to keep up with the neighbours...' (19: -6)'. All in all, 'being energy efficient is [not] a disruption to my lifestyle' (52:-5), it's about the environment and the greater good.

Cardiff factor 2: I want to be more energy efficient to save money, but I don't really know how

Five participants' Q-sorts strongly exemplified this factor, which accounted for $10 \%$ of the variance.

This factor points to financial reasons as the main motivation to conserve energy, without specifically touching on other themes. This viewpoint also highlights how even though financial savings may have been the main driver, households did not necessarily understand their energy use or how they could affect their consumption. As such, education and information campaigns that promote saving energy to save money with specific practical examples may be very effective at spurring energy efficiency in these households (Pelenur, 2013).

Even though 'I can afford my energy bills, [I'm still motivated to] conserve energy' (60: -6$)$ because 'I'm [not] happy with my energy costs' (50: $-6)$, which is why I really 'try and reduce my energy use to save money' $(23:+6)$. As such, 'I 
would like my household energy use to be more cost effective' $(44:+6)$, but while 'I [really] think about my household energy use' (28: -5) and 'try and conserve energy, sometimes it's difficult to get other people to do the same' $(36:+3)$. 'I think other people should be more aware about their energy use' $(43:+4)$, but I believe that 'families waste energy because of convenience' $(40:+5)$ and that 'woman use most of the energy at home' $(11:+3)$.

Unfortunately, while I try and conserve energy to save money, 'I don't know if my energy use is above average or below average' $(58:+5)$, nor do I 'know how much heating I use' $(8:+3)$. It really doesn't help that 'the energy and utility tariffs complicated to understand' $(2:+4)$. Personally, 'modern technology, such as plasma screens, are [not] more important to me than being energy efficient' (59: -5), but I rather heat the whole home instead of just one room (31: -5). I want to conserve energy to save money, but I don't really know how.

Cardiff factor 3 (specificity of factor 1): I'm consciously and actively energy efficient because it is plain common sense.

Three participants' Q-sorts exemplified this factor, which was the positive bipolar specificity of factor 1 accounting for $4 \%$ of the variance.

This specificity goes deeper into the environmental motivation of factor 1 and highlights how energy efficiency is not only about the environment but also about reducing waste as an overarching principal. This factor also exemplifies the viewpoint that energy efficiency is a part of personal responsibility and lists specific examples instead of using broad statements.

'I try and conserve energy out of general principle' $(39:+5)$, for example 'I turn off lighting when not in the room' $(51:+6)$, I 'heat one room rather than the whole home' $(31:+4)$, and 'I make a conscious effort to turn things off at the socket' $(48:+5)$. Basically, 'I was raised to not waste energy' (30, +3 ). However, 'I try and conserve energy, but sometimes it's difficult to get other people to do the same' $(36:+3)$. That's why I think 'schools should be teaching more about energy efficiency to kids' $(57:+5)$ and that 'parents should ensure that their kids are taught how to be energy efficient at home' (9: +3); in general, 'not enough communication is being done within households about energy issues' (41: +4).

I take an active approach to being energy efficient, 'I [always] turn off the lights or TV' (3: -5), 'I [know] how to control my heating efficiently' (12: $-6)$, and 'I [don't] forget to turn the heating off' (46: -6). We can all be doing a bit more though, for example 'I think solar panels should be built into all new properties' $(29:+6)$ and that 'energy efficient bulbs [are] good' (55: -5); 'trying to keep up with the neighbours is [not] more important than being energy efficient' (19: -6). I take an active and conscious approach to being energy efficient, because what's the point of waste?

Cardiff factor 4 (specificity of factor 1): I don't really think about energy-efficient behaviours, but I want my energy supply to be renewable and greener

Five participants' Q-sorts exemplified this factor, which was also the negative bipolar specificity of factor 1 accounting for $4 \%$ of the variance.

This factor was the bipolar viewpoint of factor 3; as such, this viewpoint focused on the responsibility of energy generation companies to promote energy efficiency instead of personal responsibility. Although environmental concerns were important to this viewpoint, the desire to be energy efficient did not always translate to action at home.

'Protecting the environment is important to me' $(27:+5)$, which is why 'I'd like there to be more environmentally friendly sources of energy' (13: $+5)$. Specifically, I believe 'we're not using sun light or wind effectively as a nation' $(25$ : +6$)$, and that 'solar panels should be built into all new properties' $(29$ : +6$)$. Ideally I 'want my energy use to be greener' $(12:+5)$ and that 'as a society, we should be self sufficient with our energy' $(53:+4)$.

However, 'I [don't always] make a conscious effort to turn things off at the socket' (48: -3) or 'use as little energy as possible' (5: -2). But definitely 'the appearance of my home is [not] more important than being energy efficient' $(17:-5)$ nor is 'trying to keep up with the neighbours...' (19: 6). I also think that 'modern technology, such as 
plasma screens, are [not] more important to me than being energy efficient' (59: -5). Even though 'I can afford my energy bills, [I still care] about conserving energy' (60: -6). I may not always think about conserving energy, but for the sake the environment, I wish my energy supply was renewable and green.

\section{Cardiff single case Q-sort (C13)}

Even though this Q-Sort did not load on any single factor, it was sufficiently different from the other responses that it warranted a more detailed analysis. This single case exemplified a unique viewpoint from the study, one which revealed a detached approach to energy use without a clear motivation to conserve energy.

A reason for this view may be that participant $\mathrm{C} 13$ did not pay any of the bills, instead his wife managed all the household finances. In the post-sort interview, the participant said that household energy use 'doesn't impact anybody else's life' and that 'if people want to waste [energy], they can because they pay for it'. Understanding this context helps explain the viewpoint. As a unique single case, this viewpoint is worth including in the discussion but was unable to be quantitatively compared to the other factors.

When it comes to energy use in my home, I don't really care. I especially don't want '... . more information about my household's energy use' (38: -6). To be fair, as a man it's not my problem since 'woman use most of the energy at home' $(11:+5)$, although 'families waste energy because of convenience' (40: +3 ). Regardless, I think '[too much] communication [is] being done within households about energy issues' (41: -5). If anything, 'schools should be teaching more about energy efficiency to kids' $(57:+3)$, not me.

While I strongly agree that 'it's our responsibility to look after the next generation's future' $(59:+6)$, 'it's a balance between what you pay for energy and what it costs you to improve energy efficiency' $(37:+5)$. For example, I admit that 'trying to keep up with the neighbours is more important than being energy efficient' $(19:+3)$ and that 'modern technology, such as plasma screens are more important to me than being energy efficient' $(59:+6)$. Even though I agree that 'the ever increasing number of gadgets is a problem for energy efficiency' $(55:+4)$. I guess I just don't agree with the importance of conserving energy.

For me, 'being energy efficient is about saving time' $(47:+4)$, which is why 'it's better to heat one room rather than the whole home' $(31:+5)$. Although, 'my house is [not] very hard to heat' (64: 4), which means that 'I [do not really] want to reduce my heating' (10: -3$)$, nor do I care about '.. . my household energy use [being] more cost effective' (44: -3$)$.

When it comes to the environment, 'I don't [particularly] believe in climate change' $(42:+3)$ and 'protecting the environment is [not that] important to me' $(27:-2)$. I don't really think 'we are too dependent on fossil fuels' $(6:-2)$ and I especially would not '.. . like there to be more environmentally friendly sources of energy' (13: -4), for example 'I [don't] think solar panels should be built into all new properties' (29: -4). We should just leave homes as they are, I don't want to see 'old homes . .improved to modern building standards' (7:-6). As a society, we're making a big deal about nothing important.

Manchester factor 1: I think about being energy efficient and the environment is important to me, but I reduce energy to save money

Twent-five participants' Q-sorts exemplified this factor accounting for $33 \%$ of the variance.

This factor presents a balanced viewpoint that considers both environmental and financial motivations to conserve energy, and as such includes a range of energy efficiency themes in a single factor. This viewpoint underscores the challenge of understanding energy use at home. This viewpoint is similar to a combination of factors 1 and 2 from Cardiff.

'It's our responsibility to look after the next generation's future' $(49:+6)$ and 'protecting the environment is important to me' $(27:+6)$, but 'I try and reduce my energy use to save money' $(23:+5)$ as opposed to just the environment. If 'I [do] think about my household energy use' (28: -5) it's because 'I would like my household energy use to more cost effective' $(44:+5)$, which is why 'I turn off lighting when not in the room' $(51:+4)$, '[don't] leave lights on for appearances' (33: -4), 
and 'I'm [not] too lazy to always turn off the lights or TV' (3: -5). Aside from just saving money, 'I use as little energy as possible' $(5:+3)$ because 'I was raised to not waste energy' $(30:+3)$, I basically 'try and conserve energy out of general principle' $(39:+5)$.

Of course, 'I [do] believe in Climate Change' (42: -6) and 'I'm concerned about the effect of energy use on the atmosphere' $(21:+4)$, so as well as taking personal responsibility, 'I'd like there to be more environmentally friendly sources of energy' $(13:+4)$ and 'think solar panels should be built into all new properties' $(29:+4)$. Especially, since 'the appearance of my home is [not] more important than being energy efficient' (17: -5), nor is 'trying to keep up with the neighbours more important than being energy efficient' (19: -6). 'Being energy efficient is [not] a disruption to my lifestyle' (52: -4) and the environment is important to me, but I reduce energy to save money.

Manchester factor 2: I don't really know how much energy I use, nor do I really care. I'm too lazy to change my lifestyle.

Five participants' Q-sorts exemplified this factor accounting for $14 \%$ of the variance.

This factor is a striking viewpoint that focuses on the comfort and lifestyle effects of energy use rather than containing motivations for energy efficiency. As a result, when considering interventions to promote energy conservation, financial incentives may not be effective on these households if the result will negatively impact on the household's lifestyle.

Energy use at home is just not that important to me. 'I don't know how much heating I use' $(8:+5)$ and I'm not ashamed to say that 'I'm too lazy to always turn off the lights or TV' $(3:+6)$. Fundamentally, 'being comfortable is more important than saving energy' $(56:+4)$, that's why 'I [leave] lights on when not in the room' (51: -5), '[don't] make a conscious effort to turn things off at the socket' (48: -6), and 'sometimes forget to turn my heating off' $(46:+4)$. Although I do agree that 'it's better to heat one room rather than the whole home' $(31:+5)$.

From a broad perspective, 'I [do] believe in climate change' (42: -6) and I do think that 'we are too dependent on fossil fuels' $(16:+6)$ since 'we're not using sunlight or wind effectively as a nation' $(25:+5)$ but I don't let it affect my lifestyle. 'I [don't] use as little energy as possible' (5: -4) and 'when I buy and appliance, I [don't check the energy ratings' (18: -5), I just buy what I want. I'm not really that fussed about thinking about my energy use, but I do agree that 'the energy and utility tariffs are complicated to understand' (2: +2 ), although I feel strongly that 'people should [not] pay the same per-unit-cost of energy regardless of how much they use' (20: -5). I don't really know how much energy I use, nor do I really care. I'm too lazy to change my lifestyle.

\section{Questionnaire results}

Using the statistical software package $\mathrm{R}$, the results from the questionnaires were correlated with the Q study factor loadings according to the tests of associations described in Table 2, and their $p$ values were adjusted to compensate for multiple comparisons using the $\mathrm{BH}$ step-up procedure. The results shown in Tables 3 and 4 are the variables which were found to be significantly correlated $(p<0.05)$ with each of the factor loadings (note the sign of the correlation to determine direction of relationship).

Since the Cardiff factor 4 loadings were the inverted loadings from factor 3 , it was expected to find an inverse relationship between the variable associations of factor 3 and 4 .

The results from the tests of association reveal that the only energy efficiency behaviour significantly correlated with Cardiff factor 1 was using washing machines at a lower temperature. Interestingly, the intent to install combined heat and power generators (CHP) was negatively correlated with the factor. Comments from the questionnaires stated that CHPs were unfamiliar, 'not appropriate' because of rental property or area, too much of a 'financial outlay' and that some participants 'needed more information about the cost and benefit'. This indicates that even though this factor highlighted energy conservation for the environment and greater good, this alone may not be enough to encourage the uptake of less-known retrofit technologies such as combined heat and power generators.

Not surprisingly for Cardiff factor 2 (I want to be more energy efficient to save money, but I don't really 
Table 3 Significantly correlated technologies, behaviours and demographic variables for Cardiff factors

\begin{tabular}{|c|c|c|c|}
\hline Questionnaire variables & $p$ value & Statistic & Test of association \\
\hline \multicolumn{4}{|c|}{ Factor 1: I think about being energy efficient for the environment and greater good } \\
\hline \multicolumn{4}{|c|}{ Technologies } \\
\hline Combined heat and power (intent) & 0.032 & -0.509 & Spearman's rho \\
\hline \multicolumn{4}{|l|}{ Behaviours } \\
\hline User lower washing machine temp. (adopt) & 0.032 & 0.510 & Point biserial \\
\hline \multicolumn{4}{|c|}{ Factor 2: I want to be more energy efficient to save money, but I don’t really know how } \\
\hline \multicolumn{4}{|l|}{ Demographics } \\
\hline Energy awareness & 0.041 & 12.321 & $F$ statistic \\
\hline \multicolumn{4}{|c|}{ Factor 3: I'm consciously and actively energy efficient because it is plain common sense. } \\
\hline \multicolumn{4}{|c|}{ Technologies } \\
\hline Wall insulation (installed) & 0.039 & 0.493 & Point biserial \\
\hline Radiator thermostats (installed) & 0.019 & 0.556 & Point biserial \\
\hline \multicolumn{4}{|c|}{ Factor 4: I don't really think about energy-efficient behaviours, but I want my energy supply to be renewable and greener } \\
\hline \multicolumn{4}{|l|}{ Technologies } \\
\hline Wall insulation (installed) & 0.039 & -0.493 & Point biserial \\
\hline Radiator thermostats (installed) & 0.019 & -0.556 & Point biserial \\
\hline
\end{tabular}

know how), the viewpoint was not correlated with any energy-efficient technologies or behaviours, although there was a relationship with this viewpoint and the questionnaire question relating to energy awareness ('how frequently do you think about your household energy'?). This positive correlation supports energy efficiency interventions, as it suggests that a portion of households are motivated to be energy efficient and think about it often, but just do not know how to go about it.
Cardiff factors 3 (I'm consciously and actively energy efficient because it is plain common sense) and 4 (I don't really think about energy efficient behaviours, but I want my energy supply to be renewable and greener) were specificities of factor 1 and represented two bipolar viewpoint. Being a specificity implies general agreement with the main factor, but from alternate perspectives. There were no associations between either factor and energy efficiency demographics or behaviours, but the installation of radiator thermostats and wall

Table 4 Significantly correlated technologies, behaviours and demographic variables for Manchester factors

\begin{tabular}{|c|c|c|c|}
\hline Questionnaire variables & $p$ value & Statistic & Test of association \\
\hline \multicolumn{4}{|c|}{ Factor 1: I think about being energy efficient and the environment is important to me, but I reduce energy to save money } \\
\hline \multicolumn{4}{|c|}{ Behaviours } \\
\hline Turn off appliances completely (desire) & 0.004 & 0.566 & Spearman's rho \\
\hline Turn off appliances completely (intent) & 0.017 & 0.488 & Spearman's rho \\
\hline Turn off appliances completely (adopt) & 0.004 & 0.578 & Point biserial \\
\hline Consciously use less (desire) & 0.017 & 0.488 & Spearman's rho \\
\hline Consciously use less (intent) & 0.017 & 0.482 & Spearman's rho \\
\hline Consciously use less (adopt) & 0.004 & 0.554 & Point biserial \\
\hline \multicolumn{4}{|c|}{ Factor 2: I don't really know how much energy I use, nor do I really care. I'm too lazy to change my lifestyle. } \\
\hline \multicolumn{4}{|l|}{ Behaviours } \\
\hline Turn off appliances completely (adopt) & 0.017 & -0.500 & Point biserial \\
\hline
\end{tabular}


insulation were positively associated with factor 3 and thereby negatively associated with factor 4 . The associations support the interpretation of the viewpoints. Factor 3 represented a proactive perspective to energy efficiency while factor 4 represented the passive perspective. An interesting result was that only the that only the simplest and most cost effective retrofit measures were associated with factor 3 , even though it represented a proactive specificity of factor 1 (environmental). This suggests that households with proactive energy efficiency viewpoints based on environmental concern may still require specific targeted incentives to encourage the uptake of energy efficiency measures, i.e. their proactive and environmental beliefs may not be enough to motivate them to install retrofit measures (Pelenur M., 2013).

For the results from Manchester, it was not possible to easily identify the two axes seen in Cardiff (save the environment and save money); rather, Manchester's factor 1 was a conflation of both themes. Two energy efficiency behaviours (desire, intention and adoption) were correlated with the viewpoint: turning off appliances completely as opposed to leaving them on standby and consciously using less energy. No retrofit technology was associated with the factor. These behavioural associations were consistent with the factor's proactive approach towards energy efficiency.

For Manchester factor 2 (I don't really know how much energy I use, nor do I really care. I'm too lazy to change my lifestyle), the only behaviour correlated with the viewpoint was a negative association with turning off appliances completely. This factor shines a light on households that may be deliberately wasting energy. Improving our understanding of the motivations and barriers to energy efficiency for these households should be the topic of future research, as reaching households who hold this viewpoint through traditional incentives (financial or social pressure) may not be effective.

\section{Comparison between Manchester and Cardiff}

The viewpoints within Manchester and Cardiff overlapped substantially when compared qualitatively, with the exception of Manchester factor 2 (apathy). On the surface, this may indicate that typical households in large UK cities consider energy use within the themes of the environment and financial concerns. The main difference between the two studies is that the apathetic viewpoint towards energy use was clearly identified in Manchester, while mostly missing in Cardiff. Another difference was that in Cardiff, the responsibility of delivering energy efficiency measures was split between the government and households. A possible reason for the difference in apathy between cities may be due to differing awareness campaigns by local councils, or large external projects that are highly visible to the community, such as the proposed tidal power plants in Wales.

Because the same statements were used in both cities, it was also possible to compare the results quantitatively between Cardiff and Manchester. This was accomplished by using each identified viewpoint (factor array) from Manchester and Cardiff as Q-sorts in a new Q study. This technique, known as second-order factor analysis, yielded a secondary set of super factors that captured any relevant family associations or differences between the original viewpoints (Watts and Stenner, 2012). Table 5 is the correlation matrix from the second-order factor analysis.

The correlation matrix in Table 5 demonstrates how the themes from Manchester and Cardiff overlap. For example, Manchester factor 1 was associated to some degree with all the Cardiff factors, which supports the interpretation that Manchester factor 1 was a conflation of the separate themes identified in Cardiff.

Alternatively, Manchester factor 2 only showed a weak association with Cardiff factor 1 and 4 . This result also supports the interpretation of Manchester factor 2, since even though it represented a disinterested and apathetic approach towards household energy use, the viewpoint still exemplified a certain degree of environmental awareness, which was also strongly revealed in Cardiff factor 1. Although unlike Cardiff factor 1, environmental awareness did not motivate households to adopt energy efficiency practices.

Cardiff factor 4 and Manchester factor 2 also shared themes of a passive approach to energy efficiency with a minimum amount of responsibility placed on the household. From the opposite pole, Manchester factor 2 was strongly not associated with Cardiff factors 2 and 3. This is in line with the interpretation of Manchester factor 2 since Cardiff factors 2 and 3 represented a proactive desire to be energy efficient.

\section{Household-shared viewpoints}

In a Q study, each participant is analysed independently using their Q-sort. However, the Q-set was created from statements that reflected a household perspective 
Table 5 Correlation matrix between Manchester and Cardiff viewpoints

Correlation matrix between Manchester and Cardiff viewpoints

\begin{tabular}{lllllll}
\hline & Manchester 1 & Manchester 2 & Cardiff 1 & Cardiff 2 & Cardiff 3 & Cardiff 4 \\
Manchester 1 & 1.00 & 0.18 & 0.85 & 0.59 & 0.73 & 0.70 \\
Manchester 2 & 0.18 & 1.00 & 0.36 & 0.09 & 0.01 & 0.45 \\
Cardiff 1 & 0.85 & 0.36 & 1.00 & 0.45 & 0.68 & 0.84 \\
Cardiff 2 & 0.59 & 0.09 & 0.45 & 1.00 & 0.44 & 0.52 \\
Cardiff 3 & 0.73 & 0.01 & 0.68 & 0.52 & 0.48 & 0.48 \\
Cardiff 4 & 0.70 & 0.45 & 0.84 & & & 1.00 \\
\hline
\end{tabular}

towards energy use. To investigate the similarities/ differences between the viewpoints of individuals living in the same household, this study did include multiple participants from the same dwelling, for example husband and wife, or mother and daughter. As such, the results for multi-participant households were examined to identify if they shared a common viewpoint, or held differing viewpoints about energy use. In Cardiff, there were six multi-participant households, while in
Manchester, there were five. The participant relationships and factor association are shown in Table 6.

Table 6 revealed that 5 out of the 11 multi-participant households did not share a common viewpoint. However, Cardiff factor 4 was as a subset of factor 1 , since it was its specificity, so it may be considered to share the same overarching theme. Likewise, having no factor association does not necessarily imply a disagreement, but rather that the participant's Q-sort was conflated, i.e.
Table 6 Multi-participant household relationships and factor associations

\begin{tabular}{|c|c|c|c|}
\hline Location & Participant & $\begin{array}{l}\text { Factor } \\
\text { association }\end{array}$ & Relationship \\
\hline \multirow[t]{2}{*}{ Cardiff 1} & $\mathrm{C} 8$ & 2 & Mother (senior) \\
\hline & $\mathrm{C} 9$ & 1 & Daughter (late 30s) \\
\hline \multirow[t]{2}{*}{ Cardiff 2} & $\mathrm{C} 14$ & 4 & Wife \\
\hline & $\mathrm{C} 15$ & 4 & Husband \\
\hline \multirow[t]{2}{*}{ Cardiff 3} & $\mathrm{C} 17$ & 1 & Husband \\
\hline & $\mathrm{C} 18$ & 1 & Wife \\
\hline \multirow[t]{2}{*}{ Cardiff 4} & $\mathrm{C} 22$ & 1 & Husband \\
\hline & $\mathrm{C} 23$ & 4 & Wife \\
\hline \multirow[t]{2}{*}{ Cardiff 5} & $\mathrm{C} 25$ & None & Husband \\
\hline & $\mathrm{C} 26$ & 1 & Wife \\
\hline \multirow[t]{2}{*}{ Cardiff 6} & $\mathrm{C} 38$ & 4 & Daughter (late 20s) \\
\hline & $\mathrm{C} 39$ & 1 & Father (late 40s) \\
\hline \multirow[t]{2}{*}{ Manchester 1} & M6 & 1 & Wife \\
\hline & M7 & 1 & Husband \\
\hline \multirow[t]{2}{*}{ Manchester 2} & M18 & None & Daughter (late 20s) \\
\hline & M19 & None & Father (late 50s) \\
\hline \multirow[t]{2}{*}{ Manchester 3} & M23 & 1 & Wife \\
\hline & M24 & 1 & Husband \\
\hline \multirow[t]{2}{*}{ Manchester 4} & M34 & 1 & Wife \\
\hline & M35 & 1 & Husband \\
\hline \multirow[t]{2}{*}{ Manchester 5} & M42 & None & Husband \\
\hline & M43 & 1 & Wife \\
\hline
\end{tabular}


loaded on multiple factors. Based on this interpretation, the results from Table 6 show only one household (Cardiff 1) with substantially different viewpoints.

For this household, the adult daughter (C9) loaded on Cardiff factor 1 (I think about being energy efficient for the environment and greater good), while the elderly mother (C8) loaded significantly on Cardiff factor 2 (I want to be more energy efficient to save money, but I don't really know how). Examining the demographics revealed that occupant $\mathrm{C} 8$ owned the home, and therefore, ownership and maintenance of a home influenced participant C8's viewpoint towards conserving energy to save money. Although, interestingly, the other two parent-child households did not show this pattern.

The overall results suggest that occupants in households with committed relationship may share an aligned viewpoint towards energy use. This insight is relevant for policy makers aiming to change household behaviour towards energy, as it indicates that a unified approach per household is justified; however, this result should be validated with a wider sample. Nevertheless, it was interesting to see that all wife/husband pairs shared very similar viewpoints towards energy use.

\section{Discussion}

The factors that emerged from Cardiff and Manchester exemplified viewpoints about household energy use from typical neighbourhoods. These viewpoints and themes emerged inductively from the general public and participants themselves, instead of a priori theory. As a result, the viewpoints were free from theoretical constraints which may have biased their narratives. Though it is possible that the researchers may have inadvertently introduced their own bias into the results, care was taken at all stages of the study design and research to minimise possible sources of such bias.

The viewpoints generally mapped onto three axes grouped by theme: saving the environment, saving money and apathy. Within the environmental axis, two bipolar specificity viewpoints were also identified: taking an active approach to energy efficiency because that is the right thing to do and taking a passive approach to being energy efficient but hoping that others will make the energy supply more efficient.

These viewpoints were not counter-intuitive, households think about energy in terms of money, the environment or do not care. Yet, this research was able to describe those viewpoints in more detail and distil the 'noisy' subjective discourse about household energy into succinct and useful summaries, as well as investigate their relationship to energy efficiency technologies and behaviours. As such, these Q-studies provided rigorous and empirical results that policy makers and retrofit professionals can apply to improve the energy performance of the built environment. Each viewpoint is discussed in more detail below.

\section{The environment}

A strong theme of environmental responsibility was strongly seen in Cardiff factor 1 and Manchester factor 1. However, these factors also showed that such environmental motivations did not always lead to the adoption of energy-efficient technology or behaviours. For example, reducing costs was a strong motivation in Manchester factor 1. This insight is in line with other research which highlight the disconnect between environmental intentions and action (Lutzenhiser 1992; Jackson 2004; Allcott and Mullainathan 2010; Upham et al. 2009; Faiers et al. 2007). A consequence of this result is that public information campaigns to encourage the adoption energy-efficient technologies/behaviours should not rely solely on an environmental or green message; rather, the specific motivations from the target audience should be well researched and understood. The results from this study show that environmental awareness alone may not be enough to spur home energy efficiency improvements.

\section{Saving money}

Unsurprisingly, reducing energy costs is a common theme across energy efficiency research (Swan and Ugursal, 2009). Although, similar to the environmental theme, saving money alone does not always lead to the uptake of energy efficiency technologies or behaviours Pelenur, 2013). Households also need to know what action to take and how to take them, as exemplified in Cardiff factor 2 (I want to be more energy efficient to save money, but I don't really know how). As such, a clear call to action (the 'how') should be presented alongside the cost savings benefits of energy efficiency. 
An interesting insight from Cardiff factor 2 was that even though households want to reduce their energy costs, some still indicated a preference to heat their whole home, thereby potentially wasting heat, as opposed to just heating the most used rooms. This indicates differing preferences for the utility of energy. In this case, adopting a loss frame to promote energy efficiency may be more effective than a gain frame, i.e. instead of promoting the monetary savings of specific energy efficiency measures/behaviours, information campaigns should highlight the costs of inefficient behaviours or poor performing technology. Highlighting costs as opposed to savings uses insights from behavioural economics that losses or disadvantages have greater impact on preferences than gains or advantages (Tversky and Kahneman, 1991).

Apathy

It should be recognised that not all households are interested or think about their energy use. Manchester factor 2 (I don't really know how much energy I use, nor do I really care. I'm too lazy to change my lifestyle) highlighted this apathy. Targeting the segment of households with this viewpoint through traditional energy efficiency interventions may not be effective. For these households, it may be more effective to frame energy efficiency interventions in terms of convenience or lifestyle improvements. For example, offering a house tidy up service alongside loft insulation. Alternatively, it may be that the most effective way to reach these households is not through direct interventions, but rather by improving the efficiency of the overall energy supply system, such as de-carbonising the grid. Systematic changes to the overall system may not change the energy demand of these households, but it will at least minimise their environmental impact.

\section{Limitations of the Q study}

A Q study is an effective research method to study subjective topics, such as home energy use. However, the results present a 'snap shot' in time, using data from today's context. As such, the insights from this study may not necessarily be applicable under different circumstances. For example, there may be substantial differences between how households in the UK view their own energy use compared to other parts of the world. However, the methodology does not aim for generalisability in a quantitative sense, instead it aims to identify individual viewpoints from within a complex topic. The overlapping results between Manchester and Cardiff suggest that the identified viewpoints may also be applicable to other large UK cities, but further research is necessary to confirm this hypothesis.

\section{Conclusions}

To better understand the energy efficiency gap, this research identified household viewpoints towards energy and linked those viewpoints with preferences towards energy efficiency technologies and behaviour. An original contribution of this research was to investigate household viewpoints towards energy in a broad study and link those viewpoints to specific technologies/behaviours, as opposed to researching a specific type of viewpoint, such as environmentalism, or technology, such as wind or solar power.

The results revealed a range of nuanced viewpoints, which mapped onto three main household themes: energy use in terms of the environment, energy in relation to money and apathy towards energy. Interestingly, there were only a small number of strong correlations between distinct energy viewpoints and specific energy efficiency technologies or behaviours. This result supports other research showing that being environmentally aware and actively concerned about energy efficiency may not in itself lead to a stated desire or intention to install energyefficient technologies (Frederiks et al., 2015).

To widen the research applicability, this study design could be repeated in fringe communities, as opposed to 'typical' neighbourhoods. The findings from such studies would allow for similarities/differences to be identified between samples. Together, the investigation of viewpoints in typical neighbourhoods, as well as fringe communities, would allow for a more holistic interpretation of the data and improve the applicability of the recommendations. Another area for further research is to investigate how these results for households can be scaled up to encourage city-wide retrofitting. Such systematic city-level action, as opposed to piecemeal upgrades, is required for the stepchange needed to improve the energy performance of the built environment and reduce national greenhouse gas emissions.

\section{Compliance with ethical standards}

Conflict of interest The authors declare that they have no conflict of interest. 


\section{Appendix}

Table 7 Q statements and factor arrays

Q statements

\begin{tabular}{|c|c|c|c|c|c|}
\hline \multicolumn{4}{|c|}{ Cardiff factors } & \multicolumn{2}{|c|}{ Man. Factors } \\
\hline 1 & 2 & 3 & 4 & 1 & 2 \\
\hline
\end{tabular}

1. I don't know how I would start going about changing my household's energy use

$\begin{array}{llllll}-1 & -1 & -2 & -2 & -1 & 3\end{array}$

2. The energy and utility tariffs are complicated to understand

$\begin{array}{llllll}2 & 4 & 0 & 4 & 1 & 2\end{array}$

3. I'm too lazy to always turn off the lights or TV

4. Even though there are government grants to install renewable generation, it is still too expensive

$\begin{array}{llllll}-3 & 1 & -5 & -1 & -5 & 6\end{array}$

5. I use as little energy as possible

6. I rather use multiple blankets or put on more layers than turn up the heating

7. Old homes should be improved to modern building standards

8. I don't know how much heating I use

9. Parents should ensure that their kids are taught how to be energy efficient at home

10. I want to reduce my heating

11. Woman use most of the energy at home

12. I don't know how to control my heating efficiently

13. I'd like there to be more environmentally friendly sources of energy

14. I want my energy use to be greener

15. I want to change how my household uses energy

16. We are too dependent on fossil fuels

17. The appearance of my home is more important than being energy efficient

18. When I buy an appliance, I check the energy ratings

19. Trying to keep up with the neighbours is more important than being energy efficient

20. People should pay the same 'per unit cost' of energy regardless of how much they use

21. I'm concerned about the effect of energy use on the atmosphere

22. I'd like to generate my own energy

23. I try and reduce my energy use to save money

24. The government is not doing enough about improving energy use

25. We're not using sunlight or wind effectively as a nation

26. I switch energy tariffs regularly to get the best deal

27. Protecting the environment is important to me

28. I never really think about my household energy use

29. I think solar panels should be built into all new properties

30. I was raised to not waste energy

31. It's better to heat one room rather than the whole home

32. People tell me what I should do to conserve energy but they don't actually do it themselves

33. I leave lights on for appearances

34. The heating in my home isn't thought out properly

35. Teenagers are not serious about saving energy

36. I try and conserve energy, but sometimes it's difficult to get other people to do the same

37. It's a balance between what you pay for energy and what it costs you to improve energy efficiency

38. I'd like more information about my household's energy use

39. I try and conserve energy out of general principle

40. Families waste energy because of convenience

$\begin{array}{llllll}0 & 3 & 1 & 2 & 2 & 0 \\ 0 & 2 & 1 & -2 & 3\end{array}$

$\begin{array}{llllll}0 & 2 & 1 & -2 & 3 & -4\end{array}$

$\begin{array}{llllll}1 & -2 & 1 & 0 & 2 & -3\end{array}$

$\begin{array}{llllll}0 & 5 & 0 & -1 & 1 & 3\end{array}$

$\begin{array}{llllll}-1 & 3 & -2 & 2 & -2 & 5\end{array}$

$\begin{array}{llllll}3 & 0 & 3 & 1 & 3 & 2\end{array}$

$\begin{array}{llllll}0 & 2 & 0 & 1 & 2 & 3\end{array}$

$\begin{array}{llllll}-3 & 3 & 1 & -2 & -2 & -4\end{array}$

$\begin{array}{llllll}-2 & 1 & -6 & 0 & -2 & -2\end{array}$

$\begin{array}{llllll}5 & 1 & 2 & 5 & 4 & 1\end{array}$

$\begin{array}{llllll}3 & 0 & 3 & 5 & 3 & 1\end{array}$

$\begin{array}{llllll}0 & 1 & 0 & 1 & 1 & -2\end{array}$

$\begin{array}{lllllll}4 & -2 & -1 & 2 & 1 & 6\end{array}$

$\begin{array}{lllllll}-5 & -3 & -3 & -5 & -5 & -1\end{array}$

$\begin{array}{llllll}1 & 0 & 2 & 0 & 0 & -5\end{array}$

$\begin{array}{lllllll}-6 & -4 & -5 & -6 & -6 & -4\end{array}$

$\begin{array}{llllll}-1 & 0 & -2 & -1 & 0 & -5\end{array}$

$\begin{array}{llllll}6 & -1 & 1 & 4 & 4 & 3\end{array}$

$\begin{array}{llllll}1 & 0 & 2 & 1 & 0 & 0\end{array}$

$\begin{array}{llllll}2 & 6 & 0 & 2 & 5 & -1\end{array}$

$\begin{array}{rrrrrr}5 & -2 & 2 & 3 & 0 & 1\end{array}$

$\begin{array}{llllll}4 & 0 & 1 & 6 & 1 & 5\end{array}$

$\begin{array}{llllll}-4 & -4 & -3 & -4 & -2 & -1\end{array}$

$\begin{array}{llllll}6 & 1 & 4 & 5 & 6 & 3\end{array}$

$\begin{array}{lllllll}-4 & -5 & -4 & -3 & -5 & -2\end{array}$

$\begin{array}{llllll}4 & 2 & 6 & 6 & 4 & 1\end{array}$

$\begin{array}{llllll}0 & 2 & 3 & 0 & 3 & 1\end{array}$

$\begin{array}{llllll}1 & -5 & 4 & 3 & 2 & 5\end{array}$

$\begin{array}{llllll}-1 & -2 & 0 & 0 & -1 & 0\end{array}$

$\begin{array}{llllll}-3 & -3 & -3 & -2 & -4 & 2\end{array}$

$\begin{array}{llllll}-1 & 0 & -3 & 3 & -1 & -1\end{array}$

$\begin{array}{llllll}-1 & -1 & 1 & -2 & 0 & 4\end{array}$

$\begin{array}{llllll}1 & 3 & 3 & 0 & 1 & -2\end{array}$

$\begin{array}{lllllll}0 & -3 & 2 & -1 & 0 & -1\end{array}$

$\begin{array}{llllll}0 & 1 & -1 & 0 & 2 & 1\end{array}$

$\begin{array}{llllll}4 & 4 & 5 & 0 & 5 & -1\end{array}$

$\begin{array}{llllll}1 & 5 & 2 & 3 & 0 & 2\end{array}$ 
Table 7 (continued)

\begin{tabular}{|c|c|c|c|c|c|c|}
\hline Q statements & \multicolumn{4}{|c|}{ Cardiff factors } & \multicolumn{2}{|c|}{ Man. Factors } \\
\hline & 1 & 2 & 3 & 4 & 1 & 2 \\
\hline 41. Not enough communication being done within households about energy issues & 1 & -1 & 4 & -1 & -1 & 0 \\
\hline 42. I don't believe in climate change & -6 & -3 & 0 & -5 & -6 & -6 \\
\hline 43. I think other people should be more aware about their energy use & 0 & 4 & 3 & 1 & 1 & 0 \\
\hline 44. I would like my household energy use to be more cost effective & 2 & 6 & 4 & 3 & 5 & 2 \\
\hline 45. Solar panels are changing the look of cities, not in a nice way & -3 & -1 & -1 & -3 & -3 & -2 \\
\hline 46. I sometimes forget to turn the heating off & -2 & 0 & -6 & -1 & -2 & 4 \\
\hline 47. Being energy efficient is about saving time & -2 & -1 & -1 & -3 & -3 & -3 \\
\hline 48. I make a conscious effort to turn things off at the socket & 1 & 3 & 5 & -3 & 3 & -6 \\
\hline 49. It's our responsibility to look after the next generation's future & 5 & 1 & 1 & 4 & 6 & 2 \\
\hline 50. I'm happy with my energy costs & -2 & -6 & -1 & -4 & -2 & -3 \\
\hline 51. I turn off lighting when not in the room & 2 & 4 & 6 & 1 & 4 & -5 \\
\hline 52. Being energy efficient is a disruption to my lifestyle & -5 & -3 & -4 & -3 & -4 & -3 \\
\hline 53. As a society, we should be self-sufficient with our energy & 3 & 0 & 0 & 4 & 1 & 0 \\
\hline 54. The ever increasing number of gadgets is a problem for energy efficiency & 3 & 1 & -1 & 2 & 0 & 4 \\
\hline 55. Energy efficient bulbs are not good & -4 & -4 & -5 & -4 & -4 & -1 \\
\hline 56. Being comfortable is more important than saving energy & -2 & -2 & -1 & -2 & -3 & 4 \\
\hline 57. Schools should be teaching more about energy efficiency to kids & 3 & 2 & 5 & -1 & 2 & 1 \\
\hline 58. I don't know if my energy use is above average or below average & -1 & 5 & -1 & 2 & -1 & 0 \\
\hline 59. Modern technology, such as plasma screens, are more important to me than being energy efficient & -5 & -5 & -4 & -5 & -3 & 1 \\
\hline 60. I can afford my energy bills, so I'm not bothered about conserving energy & -4 & -6 & -3 & -6 & -4 & 0 \\
\hline 61. I don't usually think about how to be energy efficient & -2 & -1 & -2 & -1 & -3 & -2 \\
\hline 62. Better insulation for my home means I can keep the heating on for a longer time & -3 & -4 & -2 & -4 & -1 & -4 \\
\hline 63. I don't trust the energy companies when they say they will give you advice & 2 & -2 & -2 & 1 & -1 & 0 \\
\hline 64. My house is very hard to heat & -1 & 2 & -4 & 1 & 0 & -3 \\
\hline 65. Nuclear energy is dangerous & 2 & -1 & 0 & 0 & -1 & -1 \\
\hline
\end{tabular}

Table 8 Technologies and energy efficiency behaviours included in the questionnaire

\begin{tabular}{|c|c|c|c|}
\hline \multicolumn{4}{|l|}{ Technologies } \\
\hline Loft insulation & Wall insulation & Floor insulation & Boiler insulation \\
\hline Double glazing & Triple glazing & Condensing boiler & Draught proofing \\
\hline Ground source heat pump & $\begin{array}{l}\text { Domestic combined heat } \\
\text { and power }(\mathrm{CHP})\end{array}$ & Air source heat pump & Energy efficient lighting \\
\hline Passive lighting & Micro-wind & Solar PV & Solar thermal \\
\hline Improved heating controls & Radiator thermometers & & \\
\hline \multicolumn{4}{|l|}{ Behaviours } \\
\hline $\begin{array}{l}\text { Seek energy saving advice (from } \\
\text { energy companies or government) }\end{array}$ & $\begin{array}{l}\text { Coordinate the time-of-use of appliances } \\
\text { in order to minimise peak demand }\end{array}$ & $\begin{array}{l}\text { Turn appliances off completely } \\
\text { rather than leave on stand-by }\end{array}$ & $\begin{array}{l}\text { Get rid of unnecessary } \\
\text { gadgets or appliances }\end{array}$ \\
\hline Consciously use less & $\begin{array}{l}\text { Use lower temperature for washing } \\
\text { machine }\end{array}$ & $\begin{array}{l}\text { Put on a jumper before turning } \\
\text { up the heating }\end{array}$ & \\
\hline
\end{tabular}


Table 9 Rotated factor loadings with significant loading Q-sorts

\begin{tabular}{|c|c|c|c|c|c|c|c|}
\hline \multirow[b]{2}{*}{ Q-sort } & \multicolumn{5}{|c|}{ Cardiff factors } & \multicolumn{2}{|c|}{ Manchester factors } \\
\hline & 1 & 2 & 3 & 4 & Q-sort & 1 & 2 \\
\hline C1HTY1 & $0.7068 X$ & 0.2671 & 0.2048 & -0.2048 & M1HOY1 & $0.7019 X$ & 0.342 \\
\hline C1HOY2 & $0.7661 X$ & 0.2399 & -0.1937 & 0.1937 & M1HOO2 & 0.2943 & 0.1681 \\
\hline C1HOY3 & $0.6260 X$ & 0.3757 & -0.2308 & 0.2308 & M1HOY3 & $0.7937 X$ & -0.0968 \\
\hline $\mathrm{C} 2 \mathrm{HOY} 4$ & $0.4626 X$ & 0.2787 & 0.2251 & -0.2251 & M1HTY4 & $0.6904 X$ & -0.0984 \\
\hline C1HOY5 & 0.18 & $0.5455 X$ & -0.1022 & 0.1022 & M1FTO5 & 0.2745 & 0.2602 \\
\hline C1HOY6 & 0.6971 & 0.1962 & $0.2818 X$ & -0.2818 & M1HTY6 & $0.6609 X$ & 0.0564 \\
\hline C1HOY7 & $0.7977 X$ & 0.083 & 0.236 & -0.236 & M1HTY7 & $0.6150 X$ & 0.1629 \\
\hline $\mathrm{C} 2 \mathrm{HOY} 8$ & 0.3548 & $0.4679 X$ & -0.245 & 0.245 & M1HTY8 & $0.5096 X$ & 0.1729 \\
\hline С2HTY9 & $0.4028 X$ & 0.1311 & -0.034 & 0.034 & M2HOO9 & 0.4855 & 0.4702 \\
\hline C1HOY10 & 0.3038 & $0.4632 X$ & 0.0646 & -0.0646 & M3HTY10 & -0.0529 & $0.7494 X$ \\
\hline C1HOY11 & $0.5695 X$ & 0.225 & -0.2223 & 0.2223 & M2HOY11 & 0.4713 & 0.4969 \\
\hline C2HOY12 & $0.7549 X$ & 0.1582 & -0.0357 & 0.0357 & M2HOY12 & 0.2389 & $0.4386 X$ \\
\hline C2HOY13 & -0.1006 & -0.1848 & 0.1657 & -0.1657 & M2FTY13 & 0.6272 & 0.4946 \\
\hline С2HTY14 & 0.4971 & 0.358 & -0.288 & $0.2880 X$ & M2HOY14 & 0.6752 & 0.4383 \\
\hline C2HTY15 & 0.8362 & 0.2152 & -0.3362 & $0.3362 X$ & M2HOY15 & $0.6266 X$ & 0.3505 \\
\hline C1HOY16 & $0.7354 X$ & 0.2686 & -0.0693 & 0.0693 & M2HOY16 & $0.6036 X$ & 0.2083 \\
\hline C1HOY17 & $0.8918 X$ & -0.0388 & 0.1312 & -0.1312 & M2HOO17 & $0.8025 X$ & 0.0721 \\
\hline C1HOY18 & $0.8690 X$ & 0.1059 & -0.1248 & 0.1248 & M3HTY18 & 0.4877 & 0.4628 \\
\hline С2HTY19 & 0.3896 & $0.4491 X$ & -0.1767 & 0.1767 & M3HOY19 & 0.4143 & 0.591 \\
\hline C1HOY20 & 0.6011 & 0.452 & -0.1813 & 0.1813 & M3HOO20 & 0.4857 & 0.4583 \\
\hline C3FTY21 & 0.5065 & 0.4242 & 0.1956 & -0.1956 & M2FTO21 & -0.055 & $0.3728 X$ \\
\hline $\mathrm{C} 2 \mathrm{HOY} 22$ & 0.5849 & 0.2143 & -0.338 & $0.3380 X$ & M2HOY22 & $0.4398 X$ & 0.3314 \\
\hline $\mathrm{C} 2 \mathrm{HOY} 23$ & $0.8487 X$ & 0.0944 & -0.008 & 0.008 & M2HOY23 & $0.6452 X$ & 0.2344 \\
\hline C1HTY24 & $0.8074 X$ & 0.1921 & 0.0389 & -0.0389 & M2HOY24 & $0.6323 X$ & 0.1226 \\
\hline C3HOY25 & 0.5543 & 0.4987 & 0.0474 & -0.0474 & M1HOY25 & 0.5949 & 0.3996 \\
\hline C3HOY26 & $0.4940 X$ & 0.3657 & -0.1379 & 0.1379 & M3HOO26 & -0.3191 & $0.6026 X$ \\
\hline $\mathrm{C} 3 \mathrm{FOO} 27$ & $0.6256 X$ & 0.345 & 0.1792 & -0.1792 & M1HTY27 & $0.5816 X$ & 0.1197 \\
\hline $\mathrm{C} 3 \mathrm{HOO} 28$ & 0.6715 & 0.4219 & 0.2317 & -0.2317 & M2HOY28 & $0.5953 X$ & 0.2415 \\
\hline С3HOY29 & $0.7808 X$ & 0.2196 & -0.0534 & 0.0534 & M3HOY29 & $0.6439 X$ & 0.3069 \\
\hline C4HOY30 & 0.554 & -0.0459 & $0.3009 X$ & -0.3009 & M4HOO30 & 0.0688 & $0.3714 X$ \\
\hline C4HOY31 & 0.6731 & 0.4089 & 0.2082 & -0.2082 & M3НTY31 & $0.5572 X$ & 0.1902 \\
\hline C2HOY32 & $0.7022 X$ & 0.1821 & -0.1779 & 0.1779 & M4FOO32 & $0.6262 X$ & 0.2707 \\
\hline $\mathrm{C} 3 \mathrm{HOO} 33$ & $0.6194 X$ & 0.3176 & 0.137 & -0.137 & М3НTY33 & 0.4333 & 0.7265 \\
\hline C4HOY34 & $0.6918 X$ & 0.2246 & 0.1496 & -0.1496 & M3HOO34 & $0.6497 X$ & 0.1197 \\
\hline C3FTY35 & $0.8220 X$ & 0.0412 & 0.104 & -0.104 & M3HOO35 & $0.6966 X$ & 0.1762 \\
\hline C4HOY36 & 0.4576 & 0.4588 & -0.2687 & $0.2687 X$ & M4HOY36 & $0.5637 X$ & 0.237 \\
\hline $\mathrm{C} 3 \mathrm{HOO} 37$ & $0.5397 X$ & 0.3666 & 0.2002 & -0.2002 & M4HTY37 & 0.4453 & 0.5388 \\
\hline C4HTY38 & 0.6778 & 0.0327 & -0.3847 & $0.3847 X$ & M4HOO38 & $0.6249 X$ & -0.0582 \\
\hline C4HOY39 & $0.8554 X$ & -0.0723 & -0.0997 & 0.0997 & M4HOY39 & 0.5967 & 0.5039 \\
\hline C4HTY40 & $0.6665 X$ & 0.0914 & -0.1141 & 0.1141 & M4HOY40 & $0.6820 X$ & 0.3135 \\
\hline C4HOY41 & 0.2948 & 0.4112 & $0.2941 X$ & -0.2941 & M3HTO41 & 0.6845 & 0.3786 \\
\hline С3HOY42 & $0.7252 X$ & 0.1467 & -0.1374 & 0.1374 & M3HTY42 & 0.4981 & 0.4245 \\
\hline С3HOY43 & $0.7860 X$ & 0.2277 & -0.0282 & 0.0282 & M3НTY43 & $0.7403 X$ & 0.3644 \\
\hline C4FOY44 & $0.5674 X$ & 0.3364 & -0.1926 & 0.1926 & M4HOY44 & 0.6401 & 0.4403 \\
\hline \multirow[t]{2}{*}{ C4FTY45 } & 0.0408 & $0.5981 X$ & 0.0128 & -0.0128 & M4HOO45 & $0.7884 X$ & 0.3142 \\
\hline & & & & & M4HOO46 & $0.6395 X$ & 0.288 \\
\hline \% Expl. var. & 40 & 10 & 4 & 4 & $\%$ Expl. var. & 33 & 14 \\
\hline
\end{tabular}


Open Access This article is distributed under the terms of the Creative Commons Attribution 4.0 International License (http:// creativecommons.org/licenses/by/4.0/), which permits unrestricted use, distribution, and reproduction in any medium, provided you give appropriate credit to the original author(s) and the source, provide a link to the Creative Commons license, and indicate if changes were made.

\section{References}

Abrahamse, W., \& Steg, L. (2009). How do socio-demographic and psychological factors relate to households' direct and indirect energy use and savings? Journal of Economic Psychology, 30(5), 711-720. https://doi.org/10.1016/j. joep.2009.05.006

Allcott, H., \& Mullainathan, S. (2010). Behavior and energy policy. Science, 327(5970), 1204-1205. https://doi. org/10.1126/science. 1180775

Anderson, R., \& Lipsey, M. (1978). Energy conservation and attitudes toward technology. Public Opinion Quarterly, 42(1), 17-30. https://doi.org/10.1086/268425

Balarasa, C., Gagliaa, A., Georgopouloub, E., Mirasgedisb, S., Sarafidisb, Y., \& Lalasb, D. (2007). European residential buildings and empirical assessment of the Hellenic building stock, energy consumption, emissions and potential energy savings. Building and Environment, 42(3), 1298-1314. https://doi.org/10.1016/j.buildenv.2005.11.001

Barry, J., \& Proops, J. (1999). Seeking sustainability discourses with q methodology. Ecological Economics, 28(3), 337-345. https://doi.org/10.1016/S0921-8009(98)00053-6

Becker, L., Seligman, C., Fazio, R., \& Darley, J. (1981). Relating attitudes to residential energy use. Environment and Behavior, 13(5), 590-609. https://doi.org/10.1177 /0013916581135004

Brown, S. (1980). Political subjectivity: applications of Q methodology in political science. Yale University Press.

Department of Energy and Climate Change. (2012). Housing energy fact file.

Department of Environment, Food and Rural Affairs. (2007). Public understanding of sustainable energy consumption in the home.

Department of Environment, Food and Rural Affairs. (2008). A framework for pro-environmental behaviours.

Dixon, T., \& Eames, M. (2013). Scaling up: the challenges of urban retrofit. Building Research \& Information, 41(5), 499503. https://doi.org/10.1080/09613218.2013.812432

Druckman, A., \& Jackson, T. (2008). Household energy consumption in the UK: a highly geographically and socioeconomically disaggregated model. Energy Policy, 36(8), 3177-3192. https://doi.org/10.1016/j.enpol.2008.03.021

Eden, S., Donaldson, A., \& Walker, G. (2005). Structuring subjectivities? Using Q methodology in human geography. Area, 37(4), 413-422. https://doi.org/10.1111/j.1475-4762.2005.00641.x

Eltham, D., Harrison, G., \& Allen, S. (2008). Change in public attitudes towards a cornish wind farm: Implications for planning. Energy Policy, 36(1), 23-33. https://doi.org/10.1016/j. enpol.2007.09.010
Faiers, A., Cook, M., \& Neame, C. (2007). Towards a contemporary approach for understanding consumer behaviour in the context of domestic energy use. Energy Policy, 35(8), 43814390. https://doi.org/10.1016/j.enpol.2007.01.003

Frederiks, E., Stenner, K., \& Hobman, E. (2015). Household energy use: Applying behavioural economics to understand consumer decision-making and behaviour. Renewable and Sustainable Energy Reviews, 41, 1385-1394. https://doi. org/10.1016/j.rser.2014.09.026

Guefin, D., Yust, B., \& Coopet, J. (2000). Occupant predictors of household energy behavior and consumption change as found in energy studies since 1975. Family and Consumer Sciences Research Journal, 48-80.

Hass, J., Bagley, G., \& Rogers, R. (1975). Coping with the energy crisis: effects of fear appeals upon attitudes toward energy consumption. Journal of Applied Psychology, 60(6), 754 756. https://doi.org/10.1037/0021-9010.60.6.754

Institution of Mechanical Engineers. (2009). UK 2050 energy plan mak-ing our commitment a reality.

Jackson, T. (2004). Motivating sustainable consumption a review of evidence on consumer behaviour and behavioural change. Sustainable Development Research Network.

Jaffe, A., \& Stavins, R. (1994). The energy-efficiency gap. What does it mean? Energy Policy, 22(10), 804-810. https://doi. org/10.1016/0301-4215(94)90138-4

Jones, C., \& Eiser, J. (2009). Identifying predictors of attitudes towards local onshore wind development with reference to an English case study. Energy Policy, 37(11), 4604-4614. https://doi.org/10.1016/j.enpol.2009.06.015

Kaiser, F., Wolfing, S., \& Fuhrer, U. (1999). Environmental attitude and ecological behaviour. Journal of Environmental Psychology, 19(1), 1-19. https://doi.org/10.1006 /jevp.1998.0107

Kalafatis, S., Pollard, M., East, R., \& Tsogas, M. (1999). Green marketing and ajzen's theory of planned behaviour: a crossmarket examination. Journal of Consumer Marketing, 16(5), 441-460. https://doi.org/10.1108/07363769910289550

Kelly, M. J. (2009). Retroffiting the existing UK building stock. Building Research \& Information, 37(2), 196-200. https://doi.org/10.1080/09613210802645924

Kelly, M. (2010). Energy efficiency, resilience to future climates and long-term sustainability: the role of the built environment. Philosophical Transactions of the Royal Society: Mathematical, Physical and Engineering Sciences, 368(1914), 1083-1089. https://doi.org/10.1098 /rsta.2009.0212

Krohn, S., \& Damborg, S. (1999). On public attitudes towards wind power. Renewable Energy, 16(1-4), 954-960. https://doi.org/10.1016/S0960-1481(98)00339-5

Kubier, P. (2010). Varieties of religious perception: a $Q$ methodological approach to the study of religious beliefs. Oklahoma: University of Central Oklahoma.

Lior, N. (2010). Sustainable energy development: the present (2009) situation and possible paths to the future. Energy, 35(10), 3976-3994. https://doi.org/10.1016/j.energy.2010.03.034

Low Carbon Housing Retrofit. (2012). Transforming homes from $g$ to a. Manchester: Manchester City Council.

Lutzenhiser, L. (1992). A cultural model of household energy consumption. Energy, 17(1), 47-60. https://doi.org/10.1016 /0360-5442(92)90032-U 
Mansouri, I., Newborough, M., \& Probert, D. (1996). Energy consumption in UK households: impact of domestic electrical appliances. Applied Energy, 54(3), 211-285. https://doi. org/10.1016/0306-2619(96)00001-3

McKeown, B., \& Thomas, D. (1988). Q methodology. SAGE Publications, DOI: https://doi.org/10.4135/9781412985512.

Meijer, F., Itard, L., \& Sunikka-Blank, M. (2009). Comparing European residential building stocks: performance, renovation and policy opportunities. Building Research \& Information, 37(5-6), 533-551. https://doi.org/10.1080 /09613210903189376

National Refurbishment Centre. (2012). Refurbishing the nation: gathering the evidence. Watford: BRE.

Office for National Statistics. (2013, March 31). Neighbourhood statistics. Retrieved from ONS Neighbourhood Statistics database: http://www.neighbourhood.statistics.gov. uk/dissemination/

Olsen, M. (1981). Consumers' attitudes toward energy conservation. Journal of Social Issues, 37(2), 108-131. https://doi. org/10.1111/j.1540-4560.1981.tb02628.x

Owens, S., \& Driffill, L. (2008). How to change attitudes and behaviours in the context of energy. Energy Policy, 36(12), 4412-4418. https://doi.org/10.1016/j.enpol.2008.09.031

Pelenur, M. (2013). Retrofitting the domestic built environment: investigating household perspectives towards energy efficiency technologies and behaviour. In University of Cambridge, Department of Engineering. Cambridge: University of Cambridge.

Pelenur, M., \& Cruickshank, H. (2011). The subjective view of energy in the urban built environment: what are the social factors that affect our interaction with energy? Proceedings of the 6th UNESCO Dubrovnik conference on sustainable development of energy, water and environment systems. Dubrovnik: University of Dubrovnik.

Pelenur, M., \& Cruickshank, H. (2012). Closing the energy efficiency gap: a study linking demographics with barriers to adopting energy efficiency measures in the home. Energy, 47(1), 348-357. https://doi.org/10.1016/j.energy.2012.09.058

Pelenur, M., \& Cruickshank, H. (2014). Motivations to adopting energy efficiency measures in the home. Proceedings of the ICE - Energy.

RETROFIT 2050. (2012). Re-engineering the city 2020-2050 urban foresight and transition management. Retrieved from http://www.retrofit2050.org.uk

Ritche, J., McDougall, G., \& Claxton, J. (1981). Complexities of household energy consumption and conservation. Journal of Consumer Research, 8(3), 233-242. https://doi.org/10.1086 1208860

Samuelson, C., \& Biek, M. (1991). Attitudes toward energy conservation: a confirmatory factor analysis. Journal of Applied Social Psychology, 21(7), 549-568. https://doi.org/10.1111 /j.1559-1816.1991.tb00536.x

Shove, E., Lutzenhiser, L., Guy, S. H., \& Wilhite, H. (1998). Energy and social systems. Human choice and climate change, 291-325.
Smith, J., Harre, R., \& Langenhove, L. (1995). Rethinking methods in psychology. SAGE.

Stafford, A., Gorse, C., \& Shao, L. (2012). The retrofit challenge: delivering low carbon buildings.

Stephenson, J., Barton, B., Carrington, G., Gnoth, D., Lawson, R., \& Thorsnes, P. (2010). Energy cultures: a framework for understanding energy behaviours. Energy Policy, 38(10), 6120-6129. https://doi.org/10.1016/j.enpol.2010.05.069

Swan, L., \& Ugursal, V. (2009). Modeling of end-use energy consumption in the residential sector: a review of modeling techniques. Renewable and Sustainable Energy Reviews, 13(8), 1819-1835. https://doi.org/10.1016/j.rser.2008.09.033

Thomas, D., \& Baas, L. (1996). The postelection campaign: competing constructions of the Clinton victory in 1992. The Journals of Politics, 58(2), 309-331. https://doi.org/10.2307 12960228

Thomas, D., Ribich, F., \& Frieie, J. (1982). The relationship between psychological identification with instructors and student ratings of college courses. Instructional Science, 11(2), 139-154. https://doi.org/10.1007/BF00154884

Thomas, D., McCoy, C., \& McBridge, A. (1993). Deconstructing the political spectacle: sex, race, and subjectivity in public response to the Clarence Thomas/Anita Hill "sexual harassment" hearings. American Journal of Political Science, 37(3), 699-720. https://doi.org/10.2307/2111571

Tversky, A., \& Kahneman, D. (1991). Loss aversion in riskless choice: a reference-dependent model. The Quarterly Journal of Economics, 106(4), 1039-1061. https://doi.org/10.2307 12937956

Upham, P., Whitmarsh, L., Poortinga, W., Purdam, K., Darnton, A., McLachlan, C., \& Devine-Wright, P. (2009). Public attitudes to environmental change: a selective review of theory and practice. London: Research Councils UK.

Visschers, V., \& Siegrist, M. (2013). How a nuclear power plant accident influences acceptance of nuclear power: results of a longitudinal study before and after the Fukushima disaster. Risk Analysis, 33(2), 333-347. https://doi.org/10.1111 j.1539-6924.2012.01861.x

Watts, S., \& Stenner, P. (2012). Doing Q methodological research: theory. Method and Interpretation: Sage Publications Ltd.

Weber, L. (1997). Some reflections on barriers to the efficient use of energy. Energy Policy, 25(10), 833-835. https://doi. org/10.1016/S0301-4215(97)00084-0

Wilson, C., \& Dowlatabadi, H. (2007). Models of decision making and residential energy use. Annual Review of Environment and Resources, 32(1), 169-203. https://doi.org/10.1146 /annurev.energy.32.053006.141137

Yin, R. (2009). Case study research: design and methods. London: SAGE Publications.

Zhang, T., Siebers, P., \& Aickelin, U. (2012). A three-dimensional model of residential energy consumer archetypes for local energy policy design in the UK. Energy Policy, 47, 102-110. https://doi.org/10.1016/j.enpol.2012.04.027 